ISSN 1991- 8690

Website: http://jsci.utq.edu.iq

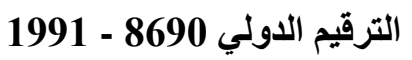

Email: utjsci@utq.edu.iq

\title{
Metabolic syndrome in Iraqi patients with psoriasis: A comparative study
}

\author{
Alaa Abdul Hassen Naif MD \\ Dept. Of Dermatology . Coll. Medicine. Thi-Qar University \\ E.mail: alaanife_77@yahoo.com Mobile: 07816954117
}

\section{$\underline{\text { Abstract }}$}

Background: Psoriasis patients are at increased risk of developing the metabolic syndrome (MS). Proinflammatory cytokines such as tumor necrosis factor- $\alpha$, interleukin-6, interleukin-23, interleukin-17 that are increased in the psoriatic plaques are known to contribute to features of MS such as hypertension, dyslipidemia and insulin resistance.

Aims: (1) To study the prevalence of MS in patients with psoriasis.

(2) To study the effect of duration of psoriasis on prevalence of MS.

Materials and Methods: A hospital based comparative study was conducted involving 40 adult patients with psoriasis and 40 age and sex-matched controls. All participants were evaluated for components of MS.

Results: Both groups included 29 males and 11 females. The mean age of the cases and controls were 39.5 years and 38.85 years, respectively. MS was present in 18 out of $40(45 \%)$ patients with psoriasis and 14 out of $40(35 \%)$ controls; odds ratio $(\mathrm{OR}=1.519 \mathrm{CI} 0.61$ to $3.73 \mathrm{p}$ value $=0.362)$. Higher age and female gender correlated with the presence of MS in psoriasis patients. Psoriasis cases with MS are older and had longer disease duration compared with psoriatic patient without MS. The difference was statistically significant.

Conclusion: There is higher prevalence of MS in psoriatic patients. However, the duration of psoriasis correlated closely with prevalence of metabolic syndrome.

Keywords:Comparative study, metabolic syndrome, psoriasis, dyslipidemia, hypertension, waist circumference, insulin resistance.

$$
\begin{aligned}
& \text { متلازمة التمثيل الذذائي في المرضى العراقيين الذين يعانون من الصدفية: دراسة مقارنه } \\
& \text { علاءعبد الحسن نايف } \\
& \text { كلية الطب - جامعة ذي قار } \\
& \text { 07816954117: alaanife_77@yahoo.com : موبايل }
\end{aligned}
$$

ألخلاصه :

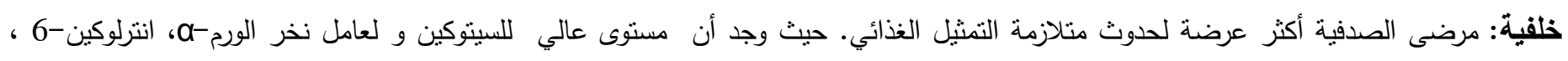

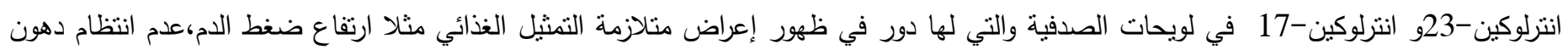
الدم ومقاومة الأنسولين.

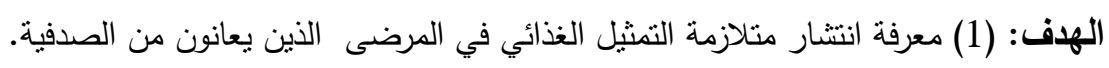

$$
\text { (2) لداراسة تأثير مدة الصدفية على متلازمة التمثيل الغذائي. }
$$

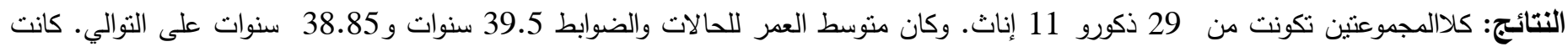

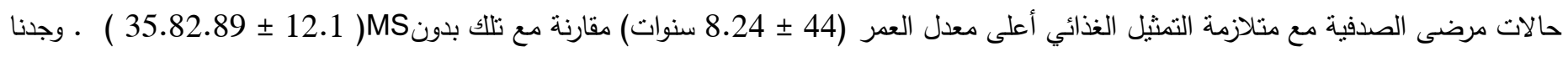
متلازمة التثثيل الغذائي في 18 من أصل 40 (45٪) المرضى الذين بعانون من الصدفية و 14 من أصل 40 (35٪) الضوابط. هذا يثير إلى ارتفاع 


\section{معدل انتشار متلازمة التمثيل الغذائي بين مرضى الصدفية. معدل أعمار أعلى ومده مرضيه أطول للمرضى المصابين بمتلازمة التمثيل الغذائي و جنس الأنتى يرتبط بشكل ملحوظ مع وجود متلازمة التمثيل الغذائي في مرضى الصدفية. الاستنتاج: نتائجنا نشير إلى أن هناك ارتفاع في نسبة متلازمة التمثيل الغذائي لدى مرضى الصدفية ، متأثرا بزيادة مدة مرض الصدفية. الكلمات المفتاحيه : دراسة مقارنه، الصدفيه، متلازمة التمثيل الغذائي،عدم انتظام دهون الدم، ارتفاع ضغط الدم، مقاومة الانسولبن، محيط الخصر.}

\section{Introduction}

Psoriasis is a chronic, T-cell mediated inflammatory disease of the skin and occasionally the nails and joints (Gisondi et al., 2007). Several studies conducted by Nijsten and Wakkee (2009) and Gottlieb, Chao and Dann (2008) have recently demonstrated that psoriasis is associated with systemic disorders such as cardiovascular disease, the metabolic syndrome (MS), cancer, chronic obstructive pulmonary disease, inflammatory bowel disease, depression and osteoporosis. The suggested causal relationship between psoriasis and associated diseases is the presence of systemic inflammation and elevated levels of cytokines such as tumor necrosis factor- $\alpha$ (TNF- $\alpha$ ) and interleukin-6 (IL-6) (Nijsten \& Wakkee, 2009). There have been recent recommendations to re-classify psoriasis from a cutaneous to a systemic disease, but the topic remains controversial (Nijsten \& Wakkee, 2009). MS, defined as a constellation of risk factors including central obesity, atherogenic dyslipidemia, hypertension and glucose intolerance, is a strong predictor of cardiovascular disease that confers a cardiovascular risk higher than the individual components as concluded by Gisondi et al. (2007) and Gulliver (2008). Increased mortality from cardiovascular disease in patients with severe psoriasis has been confirmed and psoriasis may be an independent risk factor for myocardial infarction, especially in young patients (Gisondi et al., 2007). Psoriasis is associated with MS, independent of its severity (Gisondi et al., 2007). Studies reported by Gisondi et al. (2007) and Nisten and Wakkee (2009) revealed that several factors may contribute to an unfavorable cardiovascular risk status in patients with psoriasis, such as cigarette smoking, alcohol consumption, obesity, physical inactivity, homocysteinemia, psychological stress, and depression, all of which are more prevalent in patients with psoriasis, in addition, they showed that many systemic therapies for psoriasis may also worsen cardiovascular risk factors such as hyperlipidemia, hypertension and homocysteinemia. Psoriasis affects about 3\% of the population world-wide (Gisondi et al., 2007). Recent studies have estimated prevalence of MS to be $15-24 \%$ in the general population and $30-50 \%$ among psoriasis patients. This increased frequency imposes a substantial burden on the overall health of psoriasis patients, which needs to be appropriately addressed during treatment of such patients.

Aims: To establish the prevalence of MS in patients with psoriasis and to study the effect of duration of psoriasis on prevalence of MS.

\section{Materials and Methods}

This was a hospital based comparative study, which was conducted over a period of 14 months between February 2013 and July 2014 at Department of Dermatology of Al-Hussain teaching hospital in AlNassiriah city, Iraq. During the study period, psoriasis patients and controls attending the Dermatology Department were enrolled after obtaining an informed consent.

\section{Cases}

A total of 40 patients with psoriasis satisfying the following inclusion and exclusion criteria were enrolled: Inclusion criteria: Patients with plaque psoriasis more than 18 years of age and those with psoriasis of at least 3 months duration.Exclusion criteria: Patients with psoriasis $<18$ years of age and those who have received cyclosporine, methotrexate, systemic steroid, biological agents or/and systemic retinoids therapy during the preceding three months, pustular and erythrodermic psoriasis.

\section{Controls}

Forty age- and sex-matched controls satisfying the inclusion and exclusion criteria were enrolled.Inclusion criteria: Patients attending the Dermatology Outpatient Department suffering from skin diseases other than psoriasis. Exclusion criteria: Diagnosed cases of diabetes mellitus, hypertension and dyslipidemia attending outpatient clinics in our hospital. After obtaining informed consent from the patients, relevant data such as age, sex, and duration of psoriasis were collected in a proforma. For MS, the following parameters were assessed: waist circumference, triglyceride level, high density lipoprotein (HDL), blood pressure and fasting glucose. To determine the waist circumference, measuring tape was placed around the abdomen at the level of uppermost part of the pelvic 
bone, while ensuring that the tape measure remained horizontal and was snug without causing compression on the skin. Venous blood samples were collected from the patients after they fasted overnight (at least $8 \mathrm{~h}$ ). Triglycerides and high density lipoprotein were measured using standard enzymatic procedure. Blood pressure was recorded in a sitting posture and was calculated as an average of two measurements after the patients took the rest for $5 \mathrm{~min}$. MS was diagnosed if three or more criteria of the National Cholesterol Education Program's Adult Treatment Panel III (ATPIII) were present, [5]. Data was analyzed using SPSS (version 17, SPSS Inc. Chicago, Illinois, USA), Graphpad (version 3.06, Graphpad software, San Diego, California, USA). Descriptive statistics (mean, standard deviation, and percentage), Student's t-test, Chi-square test and Fisher's exact test were used.

\section{Results}

Of the 40 cases and 40 controls, both groups consist of 29 male and 11 female. The mean age of cases was 39.5 years $( \pm 11.20)$, with age ranging from 18 to 56 years. The mean age of the controls was 38.85 years $( \pm 9.13)$.with age ranging from 18 to 50 years. There was no statistically significant difference in age between the cases and controls. Psoriasis cases with MS had a statistically significant higher mean age (44 \pm 8.24 years) compared with those without MS (35.82.89 \pm 12.1 years). Controls with MS had a no statistically significant higher mean of age $(40.28 \pm 11.55$ years $)$ compared to those without MS (38.07 \pm 7.68 years).

\section{MS in cases and controls}

The MS among patients with psoriasis was 18 out of $40(45 \%)$ and that in the control group was 14 out of $40(35 \%)$ odds ratio $(\mathrm{OR}=1.519 \mathrm{CI} 0.61$ to $3.73 \mathrm{p}$ value $=0.362$ ), this difference was not statistically significant (Chi-square test). The MS in psoriasis was significantly associated with higher age of the patients (mean age in patients cases with MS had a statistically significant higher mean age ( $44 \pm 8.24$ years) compared with those without MS $(35.82 .89 \pm 12.1$ years).The MS in psoriasis was significantly associated with the female gender, $(6 / 11(54.46 \%)$ in females vs. $12 / 29(41 \%)$ in males, $\mathrm{P}=0.032$ by Fisher's exact test).The mean age in control patients with and without MS was $40.28 \pm 11.55$ years and $38.07 \pm 7.55$ years, respectively. The MS significantly associated with female gender, $(5 / 11(45.46 \%)$ in females vs. $9 / 29(31 \%)$ in males by Fisher's exact test).

\section{Duration of psoriasis}

The mean duration of psoriasis in study was 9.83 years $( \pm 10.02)$. Mean duration of psoriasis in males was 8.18 years and in females was 14.18 years. The mean duration of psoriasis in patient with MS and in patient without is 12.75 years 7.45 years respectively. The difference was statistically significant.

Table 1- laboratory findings: comparison of cases and control

\begin{tabular}{||l|l|l|}
\hline Lab. Findings & Case $(\mathbf{n}=\mathbf{4 0})$ & Control $(\mathbf{n}=\mathbf{4 0})$ \\
\hline Triglyceride level $>1.7$ mmole & 17 & 12 \\
\hline $\begin{array}{l}\text { High density lipoprotein level }<1 \mathrm{mmole} \text { male } \\
\text { and }<1.2 \text { female }\end{array}$ & 18 & 16 \\
\hline Fasting blood sugar level $>6.1$ mmole & 19 & 14 \\
\hline $\begin{array}{l}\text { Waist circumference }>102 \mathrm{~cm} \text { male and }>88 \mathrm{~cm} \\
\text { female }\end{array}$ & 22 & $15^{*}$ \\
\hline Blood pressure $>140 / 90 \mathrm{mmHg}$ & 10 & 7 \\
\hline Metabolic syndrome & 18 & 14 \\
\hline
\end{tabular}

*the difference was statistically significant

Table2- Average fasting lipid profile, FBS and BP among cases and controls

\begin{tabular}{|lll|}
\hline Variable & control & Cases \\
\hline Fasting lipid profile (HDL) & $1.204 \mathrm{~m} \cdot \mathrm{mole}$ & $1.08 \mathrm{~m} \cdot \mathrm{mole}$ \\
Fasting blood sugar (FBS) & $6.27 \mathrm{~m} \cdot \mathrm{mole}$ & $6.658 \mathrm{~m} \cdot \mathrm{mole}$ \\
Blood pressure (BP) & $126 / 82.3 \mathrm{mmHg}$ & $127.6 / 84 \mathrm{mmHg}$ \\
Waist circumference & $97.02 \mathrm{~cm}$ & $99.56 \mathrm{~cm}$ \\
Triglyceride level & $1.708 \mathrm{~m} \cdot \mathrm{mole}$ & $1.83 \mathrm{mmole}$ \\
\hline
\end{tabular}

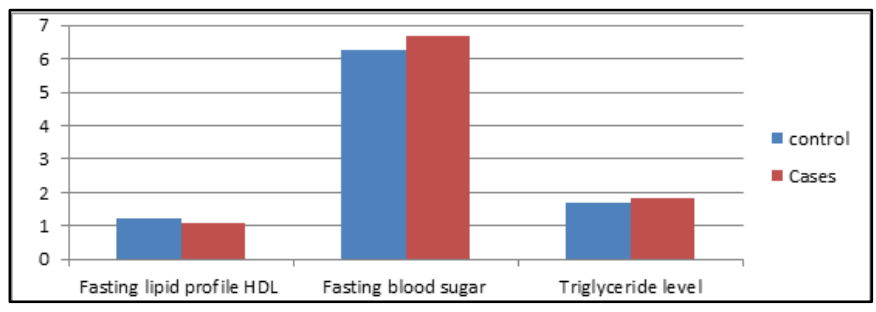

Figure 1- shows comparison between cases and controls in FBS, HDL and triglyceride 
Table3- shows comparative characteristics of psoriasis cases with and without MS

\begin{tabular}{|lll|}
\hline Characteristics & With MS & Without MS \\
\hline Age below 20 years & 0 & 1 \\
Between 21-40 years & $8(34 \%)$ & $15(66 \%)$ \\
Between41-60 years & $10(62.5 \%)$ & $6(37.5 \%)^{*}$ \\
Above 60 years & 0 & 0 \\
Sex male & 12 & 17 \\
$\quad$ Female & 6 & 5 \\
Mean age (year) & 44 & $35.8^{*}$ \\
Mean duration of disease & 12.75 & $7.45^{*}$ \\
\hline
\end{tabular}

*the difference was statistically significant

\section{Discussion}

Psoriasis patients are at increased risk of having MS. Although the correct pathogenic mechanism is not identified, pro-inflammatory cytokines like TNF- $\alpha$ and IL-6 that are found in psoriatic lesions are known to contribute to features of MS such as hypertension, dyslipidemia and insulin resistance. Several studies have found that MS is associated with psoriasis. Gisondi et al. (2007) studied 338 patients with chronic plaque psoriasis as well as 334 controls and found statistically significant higher prevalence of MS in psoriatic patients compared with the controls using National Cholesterol Education Program (NCEP) ATP III criteria $(30.1 \%$ in cases and $20.6 \%$ in controls, $\mathrm{P}=$ 0.005). Likewise, Zindanci et al. (2012) studied 115 plaque type psoriasis patients and 140 healthy individuals and found a higher prevalence of MS in cases $(53 \%)$ compared to controls $(39 \%),(\mathrm{P}<0.001)$ using International Diabetes Federation criteria). Nisa and Qazi (2010) studied 150 patients with the chronic plaque psoriasis and 150 healthy individuals and found the prevalence of MS as $28 \%$ in cases and $6 \%$ in controls, $(\mathrm{P}<0.05)$. Our study observed a higher prevalence of MS in cases (45\%) compared to controls $(35 \%)$ as per NCEP ATP III criteria. MS in psoriasis was associated with higher age in our study. Age influences the occurrence of MS in the general population as the individual components of MS are more common in the elderly population. Cases and control groups with MS in our study had statistically significant higher mean age (44. \pm 11.3 years and 40.57 \pm 9 years, respectively) compared to those without MS in their respective groups $(35.89 \pm 11.5$ years and 38.96 \pm 12.3 years, respectively). Gisondi et al. (2007) found MS in psoriasis was more common after 40 years of age. Similarly, Zindanci et al. (2012) found that MS was common in the age group of 40-59 years. Kim et al.
(2012) found higher prevalence of MS in patients older than 53 years age. Sumner, Sardi and Reed (2012) also concluded that the prevalence of MS increased with age - prevalence being $6.6 \%$ in young adults and $34 \%$ in older adults. In our study, we found MS was significantly more common in female psoriasis patients. Zindanci et al. (2012) found increased prevalence of MS in female patients $(\mathrm{P}<0.05)$. In a study run by Mebazaa et al. (2011), they found increased prevalence of MS in female patients with psoriasis (47.4\%) compared to controls $(30.1 \%),(\mathrm{P}=0.01)$. On the other hand, Gisondi et al. (2007), Nisa and Qazi (2010) and Kim et al. (2012) found no gender difference in the prevalence of MS. Zindanci et al. (2012) demonstrated higher prevalence of MS among women owing to higher waist circumference than men. Our study observed higher mean waist circumference in women compared to that in men, but the difference was not statistically significant $(\mathrm{P}>0.05)$. On studying the individual components of MS among psoriasis patients, we found that fasting blood sugar level was significantly higher among those with MS $(\mathrm{P}<0.001)$ while several other studies have demonstrated higher lipid levels in psoriasis. Dreiher, Weitzman, Davidovici, Shapiro and Cohen (2008) found a significant increase in lipid levels among psoriasis patients than in controls $(\mathrm{P}<0.001)$. Cohen et al. (2008) have found that psoriasis is associated with dyslipidemia. HDL was higher among controls with MS than among psoriasis patients with MS in our study.

\section{Conclusion}

Our results suggest that there is an association between psoriasis and MS in Southern Iraqi patients and this association is influenced by the duration of psoriasis.

\section{Recommendations}

The occurrence of MS in psoriasis needs to be examined in a larger sample of population, in addition; other factors should be considered like severity of psoriasis, smoking and BMI. Effects of systemic drugs such as biological agents on the prevalence of MS in psoriasis deserves more attention.

\section{References}

Cohen AD, Dreiher J, Saphiro Y, Vidavsky L, Vardy DA, Davidovici B, et al. (2008). Psoria- sis and diabetes: A population-based cross-sectional study. J EurAcadDeratoloVenere- ol:22:585-9.

Dreiher J, Weitzman D, Davidovici B, Shapiro J, Cohen AD. (2008). Psoriasis and dylipi- 
daemia: A population-based study. ActaDermVenereol.88:561-5.

Gisondi P, Tessari G, Conti A, Piaserico S, Schianchi S, Peserico A, et al. (2007). Prevelence of metabolic syndrome in patients with psoriasis. A hospitalbased case-control study. $\mathrm{Br}$ J Dermatol.157:6873.

Gottlieb AB, Chao C, Dann F. (2008). Psoriasis comorbidities. J Dermatolog Treat. 19:5-21.

Grundy SM, Becker D, Clark LT, Cooper RS, Denke MA, Howard WJ, et al. (2002). Wash- ington, DC: National Cholestrol Education Program, National Heart, Lung, and Blood Instute; National Institutes of Health. Third Report of the National Cholestrol Education Program Export Panel on Detection, Evaluation, and Treatment of High Blood Cholestrol In Adults (Adult Treatment Panel III) NIH Publication No. 02-5215.

http://www.nhlbi.nih.gov/guidelineslcholestrol/atp3xsu m.pdf.

Gulliver W. (2008). Long-ter prognosis in patients with psoriasis. Br J Dermatol. 159(Suppl2):2-9.

Kim GW, Park HJ, Kim HS, Kim SH, Ko HC, Kim BS, et al. (2012). Analysis of cardiovas- cular risk factors and metabolic syndrome in Korean patients with psoriasis. Ann Derma tol.24:11-5.

Mebazza A, EI Asmi M, Zidi W, Zayani Y,CheikhRouhou R, EI Ounifi S, et al. (2011). Me-

tabolic syndrome in Tunisian psoriatic patients: Prevalence and determinants.J EurAcadDermatolVenereol.25:705-9.

Nijsten T, Wakkee M.(2009). Complexity of the association between psoriasis and comorbidi-ties. J Invest Dermatol.129:1601-3.

Nisa N, Qazi MA. (2010). Prevalence of metabolic syndrome in patients with psoriasis. India-n J DermatolVenereolLeprol.76:662-5.

Sumner AD, Sardi GL, Reed JF. (2012). $3^{\text {rd }}$ Components of the metabolic syndrome differ

between young and old adults in the US population. $\mathrm{J}$ ClinHypertens (Greenwich). 14:

502-6.

Zindancy I, Albayrak O, Kavala M, Kocaturk E, Can B, Sudogan S, et al. (2012). Prevalence of metabolic syndrome in patients with psoriasis. Scientific World Journal. 2012312463. 